\title{
G

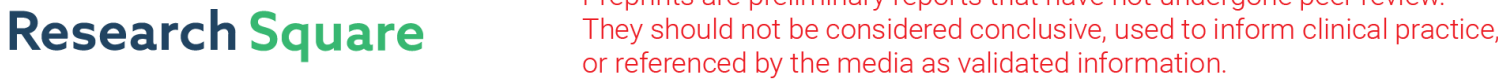 \\ Efficient anchoring of Erianthus arundinaceus chromatin introgressed into sugarcane by specific molecular markers
}

\section{Yongji Huang}

National Engineering Research Center for Sugarcane, Fujian Agriculture and Forestry University Jiayun Wu

Guangdong Key Laboratory of Sugarcane Improvement and Biorefinery, Guangdong Provincial Bioengineering Institute

\section{Xueting Li}

Fujian Agriculture and Forestry University

\section{Fan Yu}

Fujian Agriculture and Forestry University

\section{Xuguang Hu}

Fujian Agriculture and Forestry University

\section{Ling Luo}

Fujian Agriculture and Forestry University

\section{Muqing Zhang \\ Guangxi University \\ Liangnian Xu}

Fujian Agriculture and Forestry University

\section{Zuhu Deng ( $\sim$ dengzuhu@163.com )}

Fujian Agriculture and Forestry University https://orcid.org/0000-0001-8609-7461

\section{Research article}

Keywords: sugarcane, Erianthus arundinaceus, species-specific molecular marker, chromosome, suppression subtractive hybridization (SSH), Fluorescence in situ hybridization (FISH)

Posted Date: February 14th, 2020

DOI: https://doi.org/10.21203/rs.2.23548/v1

License: (c) (i) This work is licensed under a Creative Commons Attribution 4.0 International License. Read Full License 


\section{Abstract}

Erianthus arundinaceus is a valuable gene reservoir for sugarcane improvement. However, insufficient molecular markers for high-accuracy identification and tracking of the introgression status of $\mathrm{E}$. arundinaceus chromatin impede sugarcane breeding. Fortunately, suppression subtractive hybridization (SSH) technology provides an excellent opportunity for development of high-throughput E. arundinaceusspecific molecular markers at a reasonable cost. In this study, we constructed a SSH library of E. arundinaceus. In total, 288 clones E. arundinaceus-specific repetitive sequences were screened out and their distribution patterns on chromosomes were characterized by fluorescence in situ hybridization (FISH). A subtelomeric repetitive sequence Ea086 and a diffusive repetitive sequence Ea009, plus 45S rDNA-bearing E. arundinaceus chromosome repetitive sequence EalTS were developed as $\mathrm{E}$. arundinaceus-specific molecular markers, namely Ea086-128, Ea009-257, and EalTS-278, covering all the E. arundinaceus chromosomes for high-accuracy identification of putative progeny. Both Ea086-128 and Ea009-257 were successfully applied to identify the authenticity of $\mathrm{F} 1, \mathrm{BC} 1, \mathrm{BC} 2, \mathrm{BC}$, and $\mathrm{BC} 4$ progeny between sugarcane and E. arundinaceus. In addition, EalTS-278 was a 45S rDNA-bearing E. arundinaceus chromosome-specific molecular marker for rapid tracking the inherited status of this chromosome in sugarcane background. Three BC3 progeny had apparently lost the 45S rDNA-bearing E. arundinaceus chromosome. We reported herein a highly effective and reliable SSH-based technology for discovery of high-throughput E. arundinaceus-specific sequences bearing high potential as molecular markers. Given its reliability and savings in time and efforts, the method is also suitable for development of speciesspecific molecular markers for other important wild relatives to accelerate introgression of wild relatives into sugarcane.

\section{Background}

In the past, the insatiable appetite for non-renewable fossil fuels has resulted in a plethora of global climate change and environmental pollution (Gallo et al. 2016). To mitigate threats to human beings and the environment, greater use of renewable new energy sources could be the solution for the environmentally sustainable economic growth in the long run (Tessler et al. 2015). In light of the abundance of sugar and lignocellulosic materials, sugarcane has been used as the most important sugar-producing crop and a renewable substrate source for biofuels (Aguilar-Reynosa et al. 2017). Due to interspecific hybridization involving the frequent utilization of a limited number of parental clones, this has resulted in a narrow genetic base of modern sugarcane cultivars and limited resilience to biotic and abiotic stresses (Wu et al. 2014). Thus, it has become an urgent task to remedy the growing concern of a dearth of genetic variation for sugarcane breeders. To broaden genetic diversity for increased productivity and better adaptability to a wide large range of growing conditions as well as providing more robust disease resistance, it is one efficient method by harnessing the beneficial genes of the wild relatives in sugarcane breeding. As one of the most important wild relatives of sugarcane, Erianthus arundinaceus has important potential for sugarcane breeding, such as conferring a strong root system, good ratooning ability and more generally resistance to biotic and abiotic stresses (Piperidis et al. 2010). So far, a series 
of genuine progeny have been produced in different backcrossed generations (Piperidis et al. 2010). In future, a series of putative hybrid progeny will be selected as parents in sugarcane breeding programs, but recently there has been no enough efficient molecular verification of putative hybrids. Obviously, it has become increasingly important to develop adequate molecular markers covering the whole $\mathrm{E}$. arundinaceus genome for identification of progeny.

Traditionally, cytological methods and molecular markers are widely used to specifically detect the alien chromosomes and chromosomal segments in putative progeny. Genomic in situ hybridization (GISH) is a powerful cytological tool for identifying the introgression status of alien chromosomes in sugarcane background (Pachakkil et al. 2019; Piperidis et al. 2010). GISH results of progeny between sugarcane and $\mathrm{E}$. arundinaceus indicated that chromosome transmission was $\mathrm{n}+\mathrm{n}$ in $\mathrm{F}_{1}, \mathrm{BC}_{2}$, and $\mathrm{BC}_{3}$ generations, but was $2 n+n$ in $B_{1}$ generation (Piperidis et al. 2010; Wu et al. 2014). In addition, chromosome recombination between sugarcane and $\mathrm{E}$. arundinaceus has also been characterized in $\mathrm{BC}_{1}, \mathrm{BC}_{2}$, and $\mathrm{BC}_{3}$ generations (Wu et al. 2014). The major problem in developing the introgressions from $\mathrm{E}$. arundinaceus into sugarcane is the selection of recombinants, although chromosome recombination between sugarcane and $\mathrm{E}$. arundinaceus occurs only at low frequency. However, it is difficult to identify small segmental recombinants only using GISH. Furthermore, fluorescence in situ hybridization (FISH) is another cytological method involving the use of species-specific probes to detect alien chromosomes or chromosomal segments. In particular, the physical location of repetitive sequences by FISH, residing in prominent chromosomal positions, provides informative cytogenetic landmarks for unequivocal alien chromosome identification in many plant species. For example, FISH localized an E. arundinaceusspecific satellite DNA sequence in subtelomeric regions at one or both ends of most of the $E$. arundinaceus chromosomes. This E. arundinaceus-specific probe also had been used for the identification of genuine progeny between sugarcane and E. arundinaceus (Yang et al. 2019). However, the potential of FISH to identify E. arundinaceus chromosomes and chromosomal segments is restricted by a limited number of suitable probes, low throughout and inability to detect very small introgressions. Moreover, both FISH and GISH are time-consuming and need specific expertise and equipment (Villano et al. 2016).

Recent advances in molecular biology have made PCR-based markers a straightforward, affordable technique for rapid identification of putative progeny. Over several decade, molecular markers had been developed by conventional methods such as random amplified polymorphic DNA (RAPD), restriction fragment length polymorphism (RFLP), amplified fragment length polymorphism (AFLP), simple sequence repeats (SSR), inter simple sequence repeat (ISSR), and single nucleotide polymorphism (SNP) (Alix et al. 1999; Cai et al. 2005; Chen et al. 2008; Govindaraj et al. 2012; Nair and Mary 2006; Yang et al. 2018). However, only limited molecular markers was used for identification of putative progeny between sugarcane and E. arundinaceus. For instance, Govindaraj et al. reported that fifteen specific sequenced tagged microsatellite site (STMS) markers from sugarcane genome were successfully used in identifying four progeny between S. spontaneum and E. arundinaceus (Govindaraj et al. 2012). Cai et al. confirmed that two STMS markers and one 5S rDNA sequence-tagged marker allowed the identification of genuine 
intergeneric progeny in $\mathrm{F}_{1}$ and $\mathrm{BC}_{1}$ generations (Gao et al. 2015). Moreover, Alix et al. isolated four $\mathrm{E}$. arundinaceus-specific repetitive sequences by inter-Alu-like sequence-tagged PCR, which provide useful molecular markers for monitoring E. arundinaceus chromatin in sugarcane breeding programs (Alix et al. 1999). Yang et al. used the probe from E. arundinaceus-specific repetitive sequence to identify $E$. arundinaceus chromatin in introgression progeny, but the method relied on cytological techniques. Nevertheless, these conventional methods used for development of specific molecular markers are timeconsuming, laborious, and expensive (Devos and Gale 1992). In recent years, sequencing-based methods also can greatly facilitate the availability of species-specific molecular markers, such as genotyping by sequencing (GBS) and the diversity arrays technology sequencing (DarT-seq), which were benefited for some grass species such as maize, wheat, and rice (He et al. 2014; Phung et al. 2014; Yao et al. 2019). Nevertheless, developing species-specific molecular markers by using genomic tools were relatively expensive. Additionally, the genome of sugarcane and its related species is complex due to the nature of polyploids (Souza et al. 2011), such a highly complex genome poses challenges for developing speciesspecific molecular markers. Therefore, there is an urgent need to seek a high-throughput, reliable, and cost-effective method for development of species-specific molecular markers to track E. arundinaceus chromosomes or chromosomal fragments.

Fortunately, suppressive subtractive hybridization (SSH) provides a high-throughput, high-accuracy, and low-cost tool for separating DNA sequences that distinguish two closely related genomic DNA (gDNA) (Dai et al. 2004; Harakava and Gabriel 2003; Hsieh and Pan 2004; Li et al. 2004). This method does not require an in-depth knowledge of the genome and can thus be applied easily to non-model species, even the polyploids with complex genome (Dai et al. 2004; Hsieh and Pan 2004). Indeed, SSH is a combination of normalization which equalizes the abundance of DNA fragments in the target species and subtraction which excludes sequences common to both the tester and the driver (Diatchenko et al. 1996; Li et al. 2004). Thus, it is plausible that SSH will be developed for thousands of specific molecular markers in different species, enabling fast and reliable identification of putative progeny. In fact, this method had been proven to provide valuable insights into gDNA subtraction between different species. For instance, $\mathrm{Li}$ et al. reported that 617 species-specific DNA fragments were generated by SSH, and they could be used as a probe for the diagnosis of five species of the genus Dendrobrium (Li et al. 2004). Ge et al. demonstrated that 36 Lophopyrum elongatum-specific molecular markers were developed by SSH, which were successfully applicable in the detection of L. elongatum chromosomes or chromosomal fragments in wheat background (Ge et al. 2012). In this study, the SSH technology was applied for development of E. arundinaceus-specific molecular markers. A combination of FISH and PCR analysis of introgression progeny allowed the determination of the specificity and stability of these molecular markers.

Development of E. arundinaceus-specific molecular markers will make it more convenient to identify $\mathrm{E}$. arundinaceus chromatin from sugarcane background in introgression progeny and greatly improve the efficiency of E. arundinaceus introgressions into sugarcane. In future, the method is also suitable for development of species-specific molecular markers for other important wild relatives to accelerate introgression of wild relatives into sugarcane. 


\section{Methods}

\section{Plant materials}

Seven different types of accessions were used to test the specificity of primer, including E. arundinaceus, Saccharum officinarum, S. robustum, S. spontaneum, S. sinense, S. barberi, and cultivars (Table S1). Genuine progeny between sugarcane and $E$. arundinaceus identified by GISH were used for testing primer stability, including $\mathrm{F}_{1}, \mathrm{BC}_{1}, \mathrm{BC}_{2}$, and $\mathrm{BC}_{3}$ (Table S2). Putative $\mathrm{BC}_{4}$ progeny from four different cross combinations between YCE06-61 $\left(\mathrm{BC}_{3}\right)$ as the male parent and different cultivars as the female parent were identified (Table S3). All the plant materials were provided by the Hainan Sugarcane Breeding Station, Guangzhou Sugarcane Industry Research Institute, as well as the Research Institute Ruili Station, the Sugarcane Research Institute of Yunnan Agriculture Science Academy.

\section{Suppressive subtractive hybridization}

SSH was carried out as described in instructions for the Clontech PCR-Select Bacterial Genome Subtraction Kit (Clontech, USA). E. arundinaceus was assigned as the tester whereas $S$. officinarum, $S$. robustum, and $S$. spontaneum (gDNA pooled in 1:1:1 ratio) were assigned as the driver. Tester and driver gDNA were completely double digested at $37^{\circ} \mathrm{C}$ for $2 \mathrm{~h}$ with both Haell and Alul (Promega, USA) in a 50 $\mu \mathrm{L}$ reaction mixture. $100 \mathrm{ng}$ digested gDNA was ligated to $40 \mu \mathrm{M}$ of adaptor 1 and adaptor $2 \mathrm{R}$. For evaluating the subtraction efficiency, 28S rDNA primer pairs (28S-F and 28S-R) were designed. Then the adaptor-ligated tester $(22.5 \mathrm{ng})$ underwent two rounds of hybridization with the excessive driver $(225 \mathrm{ng})$ in a $4 \mu \mathrm{L}$ reaction containing $1 \times$ hybridization buffer. Two PCR amplifications were performed after subtraction. The first amplification was conducted in a $25 \mu \mathrm{L}$ reaction that included $2 \mu \mathrm{L}$ hybridization products, $1 \times$ ExTaq buffer, $1.2 \mu \mathrm{M}$ of P1 primer, $0.2 \mu \mathrm{M}$ dNTP mixture, $1 \mathrm{U}$ of ExTaq polymerase (TaKaRa ExTaq $^{T M}$, Takara Biotechnology, Inc.). PCR was conducted using the following parameters: filling the adaptors for $8 \mathrm{~min}$ at $72^{\circ} \mathrm{C}$ and denaturation for $2 \mathrm{~min}$ at $94^{\circ} \mathrm{C} ; 30$ cycles of $95^{\circ} \mathrm{C}$ for $30 \mathrm{~s}, 66^{\circ} \mathrm{C}$ for $30 \mathrm{~s}$ and $72^{\circ} \mathrm{C}$ for $1 \mathrm{~min}$, followed by a final extension at $72^{\circ} \mathrm{C}$ for $5 \mathrm{~min} .1 \mu \mathrm{L}$ of the diluted tenfold PCR products were then amplified in secondary PCR in a $25 \mu$ reaction containing $1 \times$ PCR buffer, $1 \mu \mathrm{M}$ nested PCR primer 1, $1.2 \mu \mathrm{M}$ nested PCR primer 2R, $1 \mathrm{U}$ of ExTaq polymerase, and $0.2 \mu \mathrm{M}$ dNTP mixture, under the following cycling conditions: denaturation for $2 \mathrm{~min}$ at $94^{\circ} \mathrm{C} ; 30$ cycles of $30 \mathrm{~s}$ at $94^{\circ} \mathrm{C}, 30 \mathrm{~s}$ at $68^{\circ} \mathrm{C}$ and $1 \mathrm{~min}$ at $72^{\circ} \mathrm{C}$, and a final extension for $5 \mathrm{~min}$ at $72^{\circ} \mathrm{C}$. The product of the second PCR was analyzed on $2 \%$ agarose gel stained with ethidium bromide. Secondary PCR products were purified by using a QIAquick PCR purification kit (Qiagen Inc.) and ligated into the pMD19-T-vector (TaKaRa). Plasmid DNA was purified using a Plasmid Mini kit I (OMEGA) and then quantified using a NanoVue Plus (GE Healthcare, UK). All the primer sequences were provided in Table S4.

\section{Preparation of Dig-labeled gDNAs and Reverse dot blot (RDB)}

Reverse dot blot (RDB) was performed as described by the instructions of the Digoxigenin (Dig) High Prime DNA Labeling and Detection Starter Kit I (Roche, USA) with slight modifications. The Dig-labeled gDNA of E. arundinaceus and sugarcane by nick translation was used to detect $E$. arundinaceus-specific 
clones. Aliquots of $40 \mathrm{ng}$ of plasmids were denatured at $100^{\circ} \mathrm{C}$ for $5 \mathrm{~min}$ and quickly chilled in an ice/water bath for $10 \mathrm{~min}$, and then were dotted onto Amersham Hybond $\mathrm{N}^{+}$nylon membranes (GE Healthcare, Life Sciences, Indianapolis, IN, United States). Altogether, two pairs of blots were prepared and subsequently cross-linked by using a Stratalinker ${ }^{\mathrm{TM}}$ UV Crosslinker (Stratagene, LA Jolla, CA, United States). After crosslink, the membrane was prehybridized with hybridization buffer $(6 \times$ SSC, $5 \times$ Denhardt's, $0.5 \%$ SDS, and $100 \mu \mathrm{g} / \mathrm{mL}$ sheared salmon sperm DNA) at $42^{\circ} \mathrm{C}$ for $30 \mathrm{~min}$. Hybridizations were performed overnight at $42^{\circ} \mathrm{C}$ in the hybridization buffer containing Dig-labeled probe. High stringency washes were performed following a rinse in wash solution containing $0.5 \times$ saline-sodium citrate (SSC) and $0.1 \%$ sodium dodecyl sulfate at room temperature before the blots were washed twice at $68^{\circ} \mathrm{C}$ for $15 \mathrm{~min}$ each. After incubation each for $30 \mathrm{~min}$ in blocking solution and antibody solution, respectively, the membranes were washed for $15 \mathrm{~min}$ twice in washing buffer. Then the membranes were equilibrated for $5 \mathrm{~min}$ in detection buffer and incubated for $6 \mathrm{~h}$ in color substrate solution in the dark. Finally, hybridization signals were detected with ChemiDocXRS (Bio-Rad, Hercules, CA, United States). The dot blot analysis was repeated thrice with three independent sets of blots, and the DNA of 45S rDNA plasmid was used as the positive control. A total of $288 \mathrm{E}$. arundinaceus-specific sequences were obtained and sequenced by Beijing Genomics Institute (BGI) Co., Ltd. (Shenzhen, China). Sequence data for these $E$. arundinaceus-specific sequences have been uploaded to the GenBank data library under accession numbers MN813187-MN813475.

\section{Fluorescence in situ hybridization (FISH)}

To prepare mitotic metaphase chromosomes, root tips were harvested from greenhouse-grown plants and treated with $2 \mathrm{mM}$ 8-hydroxyquinoline at room temperature for $2 \mathrm{~h}$. The root tips were then fixed in ethanol : acetic acid $(3: 1)$ fixative solution. The meristem regions were cut from root tips using a razor blade and incubated in an enzyme solution with $2 \%$ cellulase (Yakult Pharmaceutical, Tokyo, Japan) and $1 \%$ pectolyase (Sigma Chemical, St. Louis, MO, United States) at $37^{\circ} \mathrm{C}$ for $2 \mathrm{~h}$. The roots were mechanically disrupted with a metal pick and $10 \mu \mathrm{L}$ of the solution dropped onto microscope slides. At least ten mitotic metaphase chromosomes from three different root tips were prepared from each clone.

FISH was carried out essentially as described previously by Kato et al. (Kato et al. 2004). Prior to FISH, chromosomal DNA on slides were denatured in $70 \%$ formamide and $2 \times \mathrm{SSC}$ at $80^{\circ} \mathrm{C}$ for $3 \mathrm{~min}$ followed by dehydration in 70,90 , and $100 \%$ ethanol each for $5 \mathrm{~min}$ at $-20^{\circ} \mathrm{C}$. About $2 \mu \mathrm{g}$ of sheared gDNA with average size of $100 \mathrm{bp}$ prepared from $E$. arundinaceus was used as blocking DNA. The hybridization mixture $(25 \mu \mathrm{L})$ containing $50 \mathrm{ng}$ of probe, $10 \%$ dextran sulfate, $50 \%$ formamide, and $2 \times$ SSC were denatured at $95^{\circ} \mathrm{C}$ for $5 \mathrm{~min}$ prior to application to slides and hybridization overnight at $37^{\circ} \mathrm{C}$. Following by stringency washes $\left(2 \times \mathrm{SSC}, 50 \%\right.$ formamide in $2 \times \mathrm{SSC}$, and at $42^{\circ} \mathrm{C}$ in $2 \times \mathrm{SSC}$ for 5 min each), Diglabeled probes were detected by sheep-anti-digoxin-FITC (Roche, Lewes, UK) and rabbit-anti-sheep-FITC (Roche, Lewes, UK), respectively; Biotin-labeled probes were detected by Avidin D, Rhodamine 600 (XRITC) and biotinylated anti-avidin antibody (Vector Laboratories, Burlingame, CA), respectively. Chromosomes were counterstained with 4', 6-diamidino-2-phenylindole (DAPI) in a Vectashield anti-fade solution (Vector 
Laboratories, Burlingame, CA). FISH signals were captured using the AxioVision measurement module of an Axio Scope A1 Imager fluorescent microscope (Zeiss, Germany).

\section{Development, verification, and detection of $E$. arundinaceus-specific molecular markers}

The multiple sequence alignment of 45 S rDNA ITS sequences from $S$. officinarum, $S$. robustum, $S$. spontaneum, and E. arundinaceus was showed in Figure S1. The program Primer 5 was used to design oligonucleotide primers on the sequences of Ea086, Ea009, and EaITS. The primer sequences of Ea086, Ea009, and EalTS were provided in Table S4. PCR reactions were carried out in a final volume of $10 \mu \mathrm{L}$ with $50 \mathrm{ng}$ template DNA, $1 \times$ ExTaq buffer, $0.2 \mu \mathrm{M}$ dNTP mixture, $0.8 \mu \mathrm{M}$ each primer, and $1 \mathrm{U}$ of ExTaq polymerase (TaKaRa ExTaq ${ }^{\mathrm{TM}}$, Takara Biotechnology Inc.). PCR amplification was conducted using the following procedure: PCR amplifications were performed at $94^{\circ} \mathrm{C}$ for $5 \mathrm{~min}, 35$ cycles of $30 \mathrm{~s}$ at $94^{\circ} \mathrm{C}, 30 \mathrm{~s}$ at $56^{\circ} \mathrm{C}$ for annealing, and $1 \mathrm{~min}$ of extension at $72^{\circ} \mathrm{C}$, ending with $5 \mathrm{~min}$ at $72^{\circ} \mathrm{C}$. Amplification products were visualized using $2 \%$ agarose gels.

\section{Results}

\section{Construction of an E. arundinaceus-derived SSH Library}

To develop the $E$. arundinaceus-specific molecular markers, a SSH library was constructed to eliminate the homologous sequences between $E$. arundinaceus and sugarcane and enrich the DNA unique to $E$. arundinaceus. Total gDNA was isolated and appeared undegraded on $1 \%$ agarose gel (Fig. 1A). When double digested with both Haelll and Alul, the tester and driver samples appeared as a smear between 0.1 to $2 \mathrm{~kb}$ in size (Fig. 1B).

To analyze the adaptor ligation efficiency with the digested gDNA, the 28S rDNA primer pair (28S-204F/R) was designed by $28 \mathrm{~S}$ rRNA gene as a control. A clear and bright band of $204 \mathrm{bp}$ in size was amplified by PCR amplification using this primer pair. In addition, four different primer combinations were used to detect the amplify fragments that span the adaptor/DNA junctions of the tester gDNA fragments. The dim band of 300 bp in size was amplified by PCR amplification using these primer combinations (Fig. 1C). Notably, the band intensity for these PCR products was four-fold greater than that of the control tester gDNA fragments, suggesting that at least $25 \%$ of the tester gDNA fragments have adaptors on both ends and the adaptor ligation with the gDNA was successful.

Primary PCR and secondary nested PCR of the tester gDNA fragments were performed after two rounds of subtraction hybridization between testers and drivers. The observable PCR products in primary PCR and secondary nested PCR appeared as a diffuse band between 100 and 1,000 bp (Fig. 1D). Additionally, the intensity of PCR products in secondary nested PCR was markedly greater than that in primary PCR. The difference in the amplification patterns between primary PCR and secondary nested PCR indicates a successful subtraction.

PCR amplification and dot-blot screening of $E$. arundinaceus-specific clones 
To evaluate the subtraction efficiency after two rounds of subtraction, we detected the 28S rDNA in both the subtracted and non-subtracted gDNA pools using PCR amplification. If the abundance of the conserved 28S rDNA in the subtracted library was markedly reduced compared with the unsubtracted tester control, the subtraction would be efficient. As shown in Fig. 2A, the 28S rDNA fragment in the unsubtracted tester was clearly visible after 18 cycles of amplification, while 24 cycles of amplification were required in the subtracted library. The abundance of 28S rDNA was effectively reduced, which indicated that gDNA homologous to both the tester and the driver had been highly subtracted.

A total of 400 clones were obtained from the SSH library. To eliminate the false positive clones as many as possible, the nest primer set $1 / 2 \mathrm{R}$ instead of the M13F/R primer set was used to amplify the selected clones, so that the recombinant clones were detected by PCR amplification. Most clone inserts ranged from 100 to $1000 \mathrm{bp}$, and the clones with two bands or no band were excluded (Fig. 2B). In total, 329 positive clones were obtained from a subtractive library of $E$. arundinaceus, and the ratio of positive clones was $82.3 \%$. This result verified that the clones were incorporated with high efficiency.

RDB was performed to screen out the $E$. arundinaceus-specific clones by hybridization with $E$. arundinaceus and sugarcane gDNA. As predicted, similar and obvious intensity of hybridization signals was observed for the 45S rDNA positive controls. However, differences in the intensity of hybridization signals were observed for most clones, suggesting these clones had different copy numbers (Fig. $2 \mathrm{C}$ and Fig. S2). A total of 288 clones, showing stronger signals when hybridized with $E$. arundinaceus gDNA but having no or weaker signals with the sugarcane gDNA, were identified and sequenced. Thus, the results showed that the $E$. arundinaceus-specific clones we obtained have high specificity.

\section{Screening and characterization of $E$. arundinaceus-specific clones using FISH}

To screen E. arundinaceus-specific chromosome markers, a total of 100 unique clones were randomly picked in the SSH library and examined by FISH on metaphase chromosomes of $E$. arundinaceus HN9277 and HN92-105. The results showed that 86 clones produced distinct 'dot' or 'block' hybridization signals on the chromosomes. Among them, 49 clones (Ea001-Ea049) showed hybridization signals on the subtelomeric or telomeric regions on both arm ends on most of the $E$. arundinaceus chromosomes (Fig. 3A), 16 clones (Ea050-Ea065) showed hybridization signals on the subtelomeric or telomeric regions either on one arm end or both arm ends on some E. arundinaceus chromosomes (Fig. 3B), 4 clones (Ea066-Ea069) hybridized to the centromere on most of the E. arundinaceus chromosomes (Fig. 3C), 15 clones (Ea070-Ea084) showed hybridization signals at centromeric regions on some $E$. arundinaceus chromosomes (Fig. 3D), clone Ea085 showed only six hybridization signals in the centromeric regions (Fig. 3E), clone Ea086 showed dispersed localization on E. arundinaceus chromosomes (Fig. 3F). The remaining 14 clones showed no any hybridization signals on all the $E$. arundinaceus chromosomes, and thus were not used for the development of $E$. arundinaceus-specific molecular markers.

\section{Development of candidate $E$. arundinaceus-specific molecular markers}


FISH with Ea086 on E. arundinaceus mitotic chromosome spreads confirmed it was a highly dispersed repeat sequence over the length of every $E$. arundinaceus chromosomes but with fewer, less intense signals on both the end of $E$. arundinaceus chromosomes (Fig. $3 F$ ). In addition, the signals of repetitive DNA Ea009 appeared at both ends of most E. arundinaceus chromosomes (Fig. 3A). FISH results showed that both Ea086 and Ea009 were E. arundinaceus-specific in E. arundinaceus $\mathrm{HN} 92-77$ and its $\mathrm{F}_{1}$ progeny YCE96-40 (Fig. 4A and 4B; Fig. 5A and 5B). Notably, six 45S rDNA loci were located the terminal of six E. arundinaceus chromosomes (Fig. 4A and $5 \mathrm{~A}$ ). Therefore, we speculated that $45 \mathrm{~S}$ rDNA might be located at that no localization signal on part of the chromosome. This speculation was confirmed by FISH on the metaphase cell chromosomes of E. arundinaceus HN92-77 and its $\mathrm{F}_{1}$ progeny YCE96-40 (Fig. $5 \mathrm{~A}$ and $5 \mathrm{~B}$ ). Totally, three candidate clones including Ea086, Ea009, and 45S rDNA were the reliable cytogenetic markers to unambiguously detect introgressions of $E$. arundinaceus chromatin in sugarcane background. These three markers could be used for development of $E$. arundinaceus-specific molecular markers. Therefore, clones Ea086 and Ea009 were sequenced and 45S rDNA ITS sequences were obtained on NCBI databases from sugarcane and $E$. arundinaceus for primer design. Depending on the size of amplification fragments, these three molecular markers were designated as Ea086-128, Ea009257, and EalTS-278, respectively.

\section{Validation of the specificity and stability of $E$. arundinaceus-specific markers}

To confirm the specificity of $E$. arundinaceus specific markers, these three primers were used to amplify DNA in E. arundinaceus, S. officinarum, S. robustum, S. spontaneum, S. sinense, S. barberi, and cultivars, respectively. Specific bands could be amplified by these markers in gDNAs of five $E$. arundinaceus but not in that of the other species without $E$. arundinaceus chromatin (Fig. 6A, 6B, and 6C). It turned out that the $E$. arundinaceus-specific markers could be used for authenticity identification of progeny carrying $E$. arundinaceus chromatin. Notably, the specific primers Ea009-257 were able to amplify two distinct bands (Fig. 6B), and then the dimers of the repeat were sequenced to confirm the truth of the head-to-tail organization of the repeat.

To confirm the stability of these molecular markers, $\mathrm{PCR}$ detection was performed in the $\mathrm{F}_{1}, \mathrm{BC}_{1}, \mathrm{BC}_{2}$, and $\mathrm{BC}_{3}$ progeny bearing $E$. arundinaceus chromatin as determined by GISH. Both Ea086-128 and Ea009-257 amplified specific bands in all the progeny (Fig. 7A, 7B, and 7C), indicating that these two specific molecular markers of $E$. arundinaceus have good stability. EalTS-278 could amplify specific band in most progeny except for YCE06-61, YCE06-111, and YCE06-140 (Fig. 7C), indicating that the E. arundinaceusderived chromosome carrying 45S rDNA in these three clones has been eliminated. Therefore, EaITS-278 can be used as a chromosome-specific marker to permit the tracking of the $E$. arundinaceus-derived chromosome carrying 45S rDNA. These results demonstrated that the three E. arundinaceus-specific markers screened could be reliably used to identify $E$. arundinaceus chromatin or the $E$. arundinaceusderived chromosome carrying 45S rDNA.

\section{Authenticity of the putative $\mathrm{BC}_{4}$ progeny}


In order to insight the introgression status of the $E$. arundinaceus chromatin into sugarcane in putative $\mathrm{BC}_{4}$ generation, a further investigation of 96 putative $\mathrm{BC}_{4}$ progeny from four different cross combinations were carried out. Given the elimination of 45S rDNA-bearing chromosome in YCE06-61, it is no longer necessary to use EaITS-278 for PCR detection in the putative $\mathrm{BC}_{4}$ progeny. We used the $E$. arundinaceusspecific molecular markers Ea009-257 and Ea086-128 to verify the authenticity of the putative $\mathrm{BC}_{4}$ progeny in these cross combinations. Similar PCR results were obtained with these two specific molecular markers (Fig. 8A and 8B). Among them, the rate of genuine progeny of crosses was $79.2 \%$ (CP89-2143 × YCE06-61) and 75.0\% (CP94-1100 × YCE06-61), respectively, while the genuine progeny was identified with the higher rate up to $91.7 \%$ (HoCP01-564 × YCE06-61) and 95.8\% (GT 00-122 × YCE06-61), respectively.

\section{Discussion}

E. arundinaceus, a wild relative species of the genus Saccharum, contains a largely untapped reservoir of agronomically important genes for sugarcane breeding. Currently, it is inevitable that utilizing introgressive hybridization to expand the genetic base of sugarcane has been identified. Hence, sugarcane breeders had been implemented wide hybridization between sugarcane and E. arundinaceus, despite the large genetic distance between sugarcane and E. arundinaceus. More delightfully, subsequent introgression generations had also been obtained in sugarcane breeding programs (Fukuhara et al. 2013; Gao et al. 2015; Govindaraj et al. 2012; Pachakkil et al. 2019; Wu et al. 2014). Selecting introgression progeny with the best performance as good candidates are of vital importance for introgression breeding. It is evident that the availability of adequate $E$. arundinaceus-specific molecular markers can accelerate introgression breeding. Thus, the development of E. arundinaceus-specific molecular markers is expected to aid sugarcane breeders in conducting stringent screening and selection in their efforts to develop sugarcane cultivars carrying $E$. arundinaceus chromatin. However, the achievements are still not satisfactory mostly resulting from lack of E. arundinaceus-specific molecular markers. Therefore, there is an urgent need for development of E. arundinaceus-specific molecular markers to fulfill the demand for accurate and fast identification of putative progeny.

Conventional methods for development of E. arundinaceus-specific molecular markers, including RAPD, RFLP, AFLP, SSR, ISSR, and SNP, have been used for introgression detection of E. arundinaceus into sugarcane (Cai et al. 2005; D'Hont et al. 1995; Gao et al. 2015; Govindaraj et al. 2012). Nevertheless, limitations in the number of species-specific molecular markers have become the bottleneck using conventional methods-dependent techniques. More importantly, these techniques can be prone to timeconsuming, tedious and poor repeatability and are not optimal for the detection analysis of a large number of putative progeny. Therefore, it is necessary to develop new molecular markers for the discovery of highly species-specific gDNA sequences, especially in the whole genome field. Moreover, D'Hont et al. identified true progeny at the seeding stage by using the 5S rDNA sequence-tagged marker, owing to variations in sequence length in the non-transcriptional spacer region of $5 S$ rDNA cluster between sugarcane and E. arundinaceus (D'Hont et al. 1995). Due to only one $5 S$ rDNA-bearing 
chromosome in a chromosome set in E. arundinaceus, this marker can be effectively applied at an early stage in the screening program, but it is difficult to achieve accurate identification of all E. arundinaceus chromosomes in advanced generations. Additionally, cytogenetic analyses mainly involving GISH or FISH for introgression progeny have also been used to primarily characterize alien chromatin in sugarcane background. Even though GISH has proven to be reliable for characterization of introgression progeny, they are lengthy, laborious and without limitations. Moreover, to utilize the FISH technique to identify and characterize introgression progeny is still quite labor-intensive and requires species-specific sequence information for the wild relatives under study. Unfortunately, the sequence information is currently not widely available, and the cost is prohibitive to obtain for the wild relatives, especially most of them are polyploids. In our view, the PCR-based approach of utilizing E. arundinaceus-specific molecular markers to characterize introgression progeny is faster than FISH and GISH, which are traditionally employed for this purpose. Thus, sugarcane breeders are starving for development of E. arundinaceus-specific molecular markers for identification of the presence of $\mathrm{E}$. arundinaceus chromatin in putative progeny. Fortunately, SSH provides an alternative technology for development of E. arundinaceus-specific molecular markers.

Compared with conventional methods, SSH offers a simple, rapid, and affordable high-throughput screening method for separating DNA sequences that distinguish two closely related species. Although SSH only has been applied successfully to separate species-specific sequences in a few plants, this method had already proved to be capable of screening out a reservoir of species-specific molecular markers (Ge et al. 2012; Li et al. 2004; Yu et al. 2018). Notably, accurate identification of putative progeny hinges on the adequate molecular markers covering the whole genome. In SSH array, the efficient amplification of species-specific sequences by PCR is thank to that those short and high copy number fragments tend to be amplified in preference to larger and lower copy number ones (Yu et al. 2018). Highcopy-number repetitive sequences comprise most eukaryotic genomes where they are major contributors to genome evolution (Heslop-Harrison and Schwarzacher 2011; Naito et al. 2009). Repetitive sequences can be species- or genome-specific, and even chromosome-specific in many species within a taxonomic family or diverse taxa, as some repetitive sequences are highly-conserved while others are the evolutionarily fastest parts of the genome, showing pronounced differences even between closely related species (Mehrotra and Goyal 2014). Therefore, they form a reservoir of abundant DNA molecular markers covering the whole genome. Essentially, the SSH-based screening could reduce the screening task by removing a substantial number of the homologous sequences between different species and enriching the DNA sequences unique to target species (Li et al. 2004). This is achieved by a combination of normalization which equalizes the abundance of DNA fragments within the target species, and subtraction which excludes sequences that are common to the two species being compared (Li et al. 2004). This significantly reduces the effort and increases the number of species-specific molecular markers. Our results demonstrated the utility of SSH for separation of the DNA sequences unique to $\mathrm{E}$. arundinaceus and showed that SSH provides an easy, cheap, and conventional targeting species compatible PCR screening method. Its real strength is that it offers a powerful and flexible tool for development of species-specific molecular markers in higher plants with complex genome. 
In this study, a unidirectional SSH library of E. arundinaceus-specificwas constructed between E. arundinaceus and sugarcane. In total, $288 \mathrm{E}$. arundinaceus-specific sequences were obtained by SSH, suggesting that this $\mathrm{SSH}$-based screening method could provide a highly parallel platform to efficiently obtain a larger number of species-specific sequences from a bulky and complex genome of target species. FISH screening trials of SSH library resulted in the isolation of a large number of repetitive sequences located on all the chromosome end except on 45S rDNA and a diffusive repetitive sequence on all chromosomes except the chromosome end, respectively (Fig. 3A and 3F). Therefore, a subtelomeric repetitive sequence Ea086 and a diffusive repetitive sequence Ea009, plus 45S rDNA-bearing E. arundinaceus chromosome repetitive sequence EalTS, were developed as E. arundinaceus-specific molecular markers, covering all the $\mathrm{E}$. arundinaceus chromosomes for high-accuracy identification of putative progeny. Hence, a large number of putative progeny could be easily and economically identified by PCR detection.

Consistent PCR detection results from both Ea086-128 and Ea009-257 were obtained in $\mathrm{F}_{1}, \mathrm{BC}_{1}, \mathrm{BC}_{2}$, and $\mathrm{BC}_{3}$ progeny between sugarcane and $\mathrm{E}$. arundinaceus, and the $\mathrm{PCR}$ detection results determined are highly line with previous GISH results (Huang et al. 2015; Wu et al. 2014), validating these two markers could be stably inherited in various progeny of different generations with $E$. arundinaceus chromatin (Fig. 7). Consequently, these two markers were successfully applied to further identify the authenticity of $96 \mathrm{BC}_{4}$ progeny between sugarcane and $\mathrm{E}$. arundinaceus. These universal markers we developed are particularly valuable since they can be applied to easily track the transmission of E. arundinaceus chromosomes over generations, given the possibility of E. arundinaceus chromosome elimination in advanced generations. Furthermore, the developed molecular marker Ea009-257 was confirmed as a tandem repeat (Fig. 6C). Many studies have shown that satellite DNAs comprising head-to-tail tandem repeats are believed to be the most dynamic components (Biscotti et al. 2015; Cai et al. 2014; He et al. 2015), undergoing the most rapid changes in the number and position of sites within a short evolutionary period (Mehrotra and Goyal 2014). It may also explain the largest number of E. arundinaceus-specific sequences from the SSH library. Noteworthy is that EalTS-278 was a 45S rDNA-bearing E. arundinaceus chromosome-specific molecular marker for rapid tracking the inherited status of this chromosome in sugarcane background. We found that three $\mathrm{BC}_{3}$ progeny, namely YCE06-61, YCE06-111, and YCE06-140, had apparently lost the 45S rDNA-bearing E. arundinaceus chromosome. In the light of GISH results, we could rule out that chromosome rearrangements between sugarcane and $\mathrm{E}$. arundinaceus contribute to a loss or transposition of 45S rDNA sequences in these progeny. Taking together, these results demonstrated that the SSH-based technology is a highly effective and reliable approach for development of E. arundinaceus-specific molecular markers from a bulky and complex genome species. Given its reliability and savings in time and efforts, the method is also suitable for development of species-specific molecular markers for other important wild relatives to accelerate introgression of alien chromatin into sugarcane. Nevertheless, we do not recommend the replacement of GISH or FISH with molecular markers. Rather, it is highly encouraged that the integration of efficient molecular markers with GISH or FISH strategies in sugarcane breeding programs to accelerate the process and improve outcomes. 


\section{Conclusion}

In this study, the SSH technology is demonstrated to be a highly effective and reliable approach for development of E. arundinaceus-specific molecular markers. These molecular markers developed are very beneficial for progressive research in sugarcane breeding, particularly in the process of developing and characterizing introgression progeny. Also, a further analysis revealed remarkable stability of Ea086-128 and Ea009-257 in different generations, as they can be deployed to characterize introgression progeny carrying E. arundinaceus chromosomes. Hence, their high stability will further broaden their scope of application in putative $\mathrm{BC}_{4}$ generation and even more advanced generations. Additionally, EalTS-278 could be developed for rapid tracking the inherited status of the $45 \mathrm{~S}$ rDNA-bearing $\mathrm{E}$. arundinaceus chromosome in sugarcane background. Altogether, these findings indicate that integrating the markers with GISH or FISH strategies would accelerate development and characterization of introgression progeny. In future, the method is also suitable for development of species-specific molecular markers for other important wild relatives to accelerate introgression of wild relatives into sugarcane.

\section{Abbreviations}

suppression subtractive hybridization: $\mathrm{SSH}$; genomic in situ hybridization: GISH; fluorescence in situ hybridization: FISH; random amplified polymorphic DNA: RAPD; restriction fragment length polymorphism: RFLP; amplified fragment length polymorphism: AFLP; simple sequence repeats: SSR; inter simple sequence repeat: ISSR; single nucleotide polymorphism: SNP; specific sequenced tagged microsatellite site: STMS; genotyping-by-sequencing: GBS; diversity arrays technology sequencing: DarTseq; genomic DNA: gDNA

\section{Declarations}

\section{Acknowledgements}

We thank the Research Institute Ruili Station, the Sugarcane Research Institute of Yunnan Agriculture Science Academy, as well as the Hainan Sugarcane Breeding Station, Guangzhou Sugarcane Industry Research Institute for providing the plant materials used in this study.

\section{Authors' contributions}

Y. H., J. W., and Z. D. designed the research. Y. H., X. L., and F. Y. performed the experiments. Y. H., J. W., X. L., F. Y., X. H., L. L., M. Z., L. X., and Z. D. analyzed the results. Y. H., J. W., and Z. D. wrote the manuscript. All authors read and approved the final manuscript.

\section{Funding}

This research was funded by the National Natural Science Foundation of China (31771863, http://www.nsfc.gov.cn/) and supported by an earmarked fund for Modern Agriculture Technology of 
China (CARS-170106). This project was also granted from the State Key Laboratory for Conservation and Utilization of Subtropical Agro-Bioresources (SKLCUSA-a201912 and SKLCUSA-b201806) and supported by Special Fund for Science and Technology Innovation of Fujian Agriculture and Forestry University (KFA17168A, KFA17525A, and KFA17169A).

\section{Availability of data and materials}

All data generated or analysed during this study are included in this published article and its supplementary information files.

\section{Ethics approval and consent to participate}

Not applicable.

\section{Consent for publication}

Not applicable.

\section{Competing interests}

The authors declare that they have no competing interests.

\section{References}

Aguilar-Reynosa A, Romani A, Rodriguez-Jasso RM, Aguilar CN, Garrote G, Ruiz HA (2017) Microwave heating processing as alternative of pretreatment in second-generation biorefinery: An overview Energ Convers Manage 136:50-65 doi:10.1016/j.enconman.2017.01.004

Alix K, Paulet F, Glaszmann J-C, D'Hont A (1999) Inter-Alu-like species-specific sequences in the Saccharum complex Theor Appl Genet 99:962-968 doi:10.1007/s001220051403

Biscotti MA, Olmo E, Heslop-Harrison JS (2015) Repetitive DNA in eukaryotic genomes Chromosome research : an international journal on the molecular, supramolecular and evolutionary aspects of chromosome biology 23:415-420 doi:10.1007/s10577-015-9499-z

Cai Q, Aitken K, Deng HH, Chen XW, Fu C, Jackson PA, McIntyre CL (2005) Verification of the introgression of Erianthus arundinaceus germplasm into sugarcane using molecular markers Plant Breed 124:322-328 doi:10.1111/j.1439-0523.2005.01099.x

Cai Z et al. (2014) Differential genome evolution and speciation of Coix lacryma-jobi L. and Coix aquatica Roxb. hybrid guangxi revealed by repetitive sequence analysis and fine karyotyping BMC genomics 15:1025 doi:10.1186/1471-2164-15-1025 
Chen JW, Jackson PA, Lao FY, Liu R (2008) Identification of $\mathrm{BC}_{2}$ Progeny from Saccharum officinarum $\times$ Erianthus arundinaceus by ISSR Markers Sugar Crops of China

D'Hont A, Rao PS, Feldmann P, Grivet L, Islam-Faridi N, Taylor P, Glaszmann JC (1995) Identification and characterisation of sugarcane intergeneric hybrids, Saccharum officinarum x Erianthus arundinaceus, with molecular markers and DNA in situ hybridisation Theor Appl Genet 91:320-326 doi:10.1007/bf00220894

Dai ZY, Mao XX, Magnuson JK, Lasure LL (2004) Identification of genes associated with morphology in Aspergillus niger by using suppression subtractive hybridization Appl Environ Microb 70:2474-2485 doi:10.1128/Aem.70.4.2474-2485.2004

Devos KM, Gale MD (1992) The use of random amplified polymorphic DNA markers in wheat Theor Appl Genet 84:567-572 doi:10.1007/bf00224153

Diatchenko L et al. (1996) Suppression subtractive hybridization: a method for generating differentially regulated or tissue-specific cDNA probes and libraries Proc Natl Acad Sci USA 93:6025-6030 doi:10.1073/pnas.93.12.6025 \%J Proceedings of the National Academy of Sciences

Fukuhara S, Terajima Y, Irei S, Sakaigaichi T, Ujihara K, Sugimoto A, Matsuoka M (2013) Identification and characterization of intergeneric hybrid of commercial sugarcane (Saccharum spp. hybrid) and Erianthus arundinaceus (Retz.) Jeswiet Euphytica 189:321-327 doi:10.1007/s10681-012-0748-3

Gallo AB, Simoes-Moreira JR, Costa HKM, Santos MM, dos Santos EM (2016) Energy storage in the energy transition context: A technology review Renew Sust Energ Rev 65:800-822 doi:10.1016/j.rser.2016.07.028

Gao YJ, Liu XH, Zhang RH, Zhou H, Liao JX, Duan WX, Zhang GM (2015) Verification of Progeny from Crosses Between Sugarcane (Saccharum spp.) and an Intergeneric Hybrid (Erianthus arundinaceus $\mathrm{X}$ Saccharum spontaneum) with Molecular Makers Sugar Tech 17:31-35 doi:10.1007/s12355-014-0310-9

Ge J, Chen S, Gao Y, Gao Y, Zhu X, Huang Z, Chen J (2012) Development of genome-specific molecular markers for Lophopyrum elongatum based on suppression subtractive hybridization Acta Agron Sin 38:1818-1826

Govindaraj P, Balamurugan A, Natarajan US (2012) Identification of intergeneric hybrids between Erianthus arundinaceus and Saccharum spontaneum through STMS markers Int Sugar J 114:350-+

Harakava R, Gabriel DW (2003) Genetic differences between two strains of Xylella fastidiosa revealed by suppression subtractive hybridization Appl Environ Microb 69:1315-1319 doi:10.1128/Aem.69.2.13151319.2003 
He J, Zhao X, Laroche A, Lu Z-X, Liu H, Li Z (2014) Genotyping-by-sequencing (GBS), an ultimate markerassisted selection (MAS) tool to accelerate plant breeding Front Plant Sci 5:484-484 doi:10.3389/fpls.2014.00484

He Q, Cai Z, Hu T, Liu H, Bao C, Mao W, Jin W (2015) Repetitive sequence analysis and karyotyping reveals centromere-associated DNA sequences in radish (Raphanus sativus L.) BMC plant biology 15:105 doi:10.1186/s12870-015-0480-y

Heslop-Harrison JS, Schwarzacher T (2011) Organisation of the plant genome in chromosomes The Plant journal : for cell and molecular biology 66:18-33 doi:10.1111/j.1365-313X.2011.04544.x

Hsieh WJ, Pan MJ (2004) Identification Leptospira santarosai serovar shermani specific sequences by suppression subtractive hybridization FEMS microbiology letters 235:117-124 doi:10.1016/j.femsle.2004.04.024

Huang YJ et al. (2015) Characterization of Chromosome Inheritance of the Intergeneric $\mathrm{BC}_{2}$ and $\mathrm{BC}_{3}$ Progeny between Saccharum spp. and Erianthus arundinaceus PLoS One 10:13 doi:10.1371/journal.pone.0133722

Kato A, Lamb JC, Birchler JA (2004) Chromosome painting using repetitive DNA sequences as probes for somatic chromosome identification in maize Proc Natl Acad Sci USA 101:13554-13559 doi:10.1073/pnas.0403659101

Li TX, Wang JK, Bai YF, Sun XD, Lu ZH (2004) A novel method for screening species-specific gDNA probes for species identification Nucleic Acids Res 32:8 doi:10.1093/nar/gnh041

Mehrotra S, Goyal V (2014) Repetitive sequences in plant nuclear DNA: types, distribution, evolution and function Genom Proteom Bioinf 12:164-171 doi:10.1016/j.gpb.2014.07.003

Nair NV, Mary S (2006) RAPD analysis reveals the presence of Indian and Indonesian forms of Erianthus arundinaceus (Retz.) Jeswiet. in the Andaman-Nicobar Islands, India Curr Sci India 90:1118-1122

Naito K et al. (2009) Unexpected consequences of a sudden and massive transposon amplification on rice gene expression Nature 461:1130-1134 doi:10.1038/nature08479

Pachakkil B, Terajima Y, Ohmido N, Ebina M, Irei S, Hayashi H, Takagi H (2019) Cytogenetic and agronomic characterization of intergeneric hybrids between Saccharum spp. hybrid and Erianthus arundinaceus Sci Rep 9:1748 doi:10.1038/s41598-018-38316-6

Phung NTP et al. (2014) Characterization of a panel of Vietnamese rice varieties using DArT and SNP markers for association mapping purposes BMC plant biology 14:371 doi:10.1186/s12870-014-0371-7

Piperidis N, Chen JW, Deng HH, Wang LP, Jackson P, Piperidis G (2010) GISH characterization of Erianthus arundinaceus chromosomes in three generations of sugarcane intergeneric hybrids Genome 
Souza GM et al. (2011) The Sugarcane Genome Challenge: Strategies for Sequencing a Highly Complex Genome Trop Plant Biol 4:145-156

Tessler ZD, Vorosmarty CJ, Grossberg M, Gladkova I, Aizenman H, Syvitski JPM, Foufoula-Georgiou E (2015) Profiling risk and sustainability in coastal deltas of the world Science 349:638-643 doi:10.1126/science.aab3574

Villano C, Miraglia V, lorizzo M, Aversano R, Carputo D (2016) Combined Use of Molecular Markers and High-Resolution Melting (HRM) to Assess Chromosome Dosage in Potato Hybrids J hered 107:187-192 doi:10.1093/jhered/esv094

Wu JY et al. (2014) Unexpected Inheritance Pattern of Erianthus arundinaceus Chromosomes in the Intergeneric Progeny between Saccharum spp. and Erianthus arundinaceus PLoS One 9:9 doi:10.1371/journal.pone.0110390

Yang S et al. (2018) A new method based on SNP of nrDNA-ITS to identify Saccharum spontaneum and its progeny in the genus Saccharum PLoS One 13:e0197458 doi:10.1371/journal.pone.0197458

Yang $S$ et al. (2019) Chromosome transmission in $\mathrm{BC}_{4}$ progenies of intergeneric hybrids between Saccharum spp. and Erianthus arundinaceus (Retz.) Jeswiet Sci Rep 9:2528 doi:10.1038/s41598-01938710-8

Yao F et al. (2019) Characterization of molecular diversity and genome-wide association study of stripe rust resistance at the adult plant stage in Northern Chinese wheat landraces BMC Genetics 20:38 doi:10.1186/s12863-019-0736-x

Yu F et al. (2018) An improved suppression subtractive hybridization technique to develop speciesspecific repetitive sequences from Erianthus arundinaceus (Saccharum complex) BMC plant biology 18:269 doi:10.1186/s12870-018-1471-6

\section{Figures}



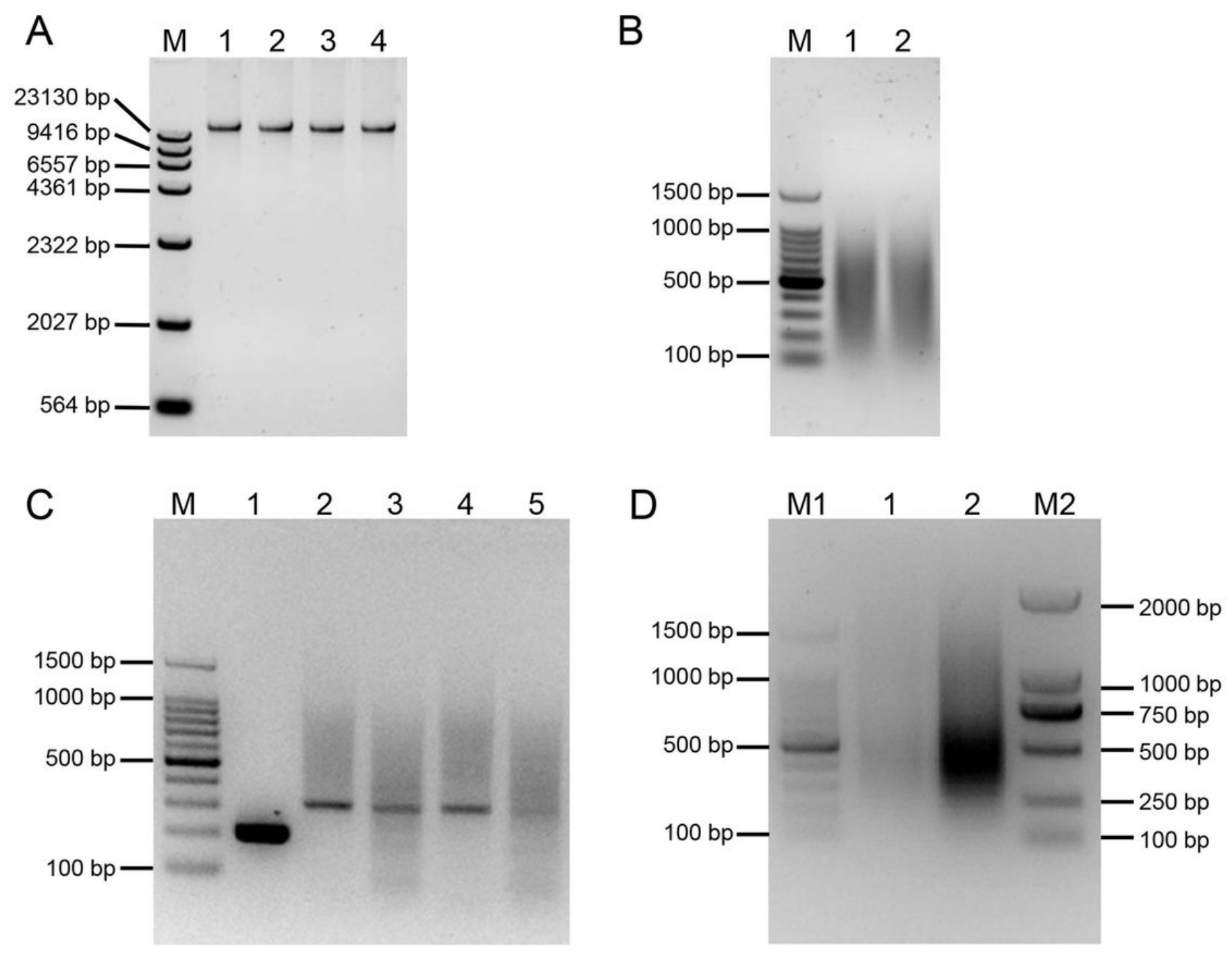

\section{Figure 1}

The electrophoresis result of an E. arundinaceus-derived SSH Library. (A) The electrophoresis result of gDNA. M: $\lambda D N A / H i n d I I I$ digest DNA Marker; 1: E. arundinaceus HN92-77; 2ХS. officinarum Badila; 3: S. robustum 51NG3; 4: S. spontaneum YN82-114. (B) Enzyme digestion of gDNA. M1: 100 bp DNA Ladder; 1: The digested product of gDNA from $\mathrm{E}$. arundinaceus HN92-77; 2: The digested product of gDNA from S. officinarum Badila, S. robustum 51NG3, and S. spontaneum YN82-114 by mixing equal quantity. (C) Detection result of the adaptor ligation efficiency. M: 100 bp DNA Ladder; 1: Amplification with primer pair 28S-204-F/28S-204-R by using tester with adaptor 1-ligated and adaptor 2R-ligated; 2: Amplification with primer pair PCR primer 1/28S-204-F by using tester with adaptor 1-ligated; 3: Amplification with primer pair PCR primer 1/28S-204-R by using tester with adaptor 1-ligated; 4: Amplification with primer pair PCR primer 1/28S-204-F by using tester with adaptor 2R-ligated; 5: Amplification with primer pair PCR primer 1/28S-204-R by using tester with adaptor 2R-ligated. (D) Detection result of two suppression PCR. M1: 100 bp DNA Ladder; 1: Primary PCR was performed with primer 1; 2: Secondary PCR was performed with both Nest primer 1 and Nest primer 2; M2: D2000 DNA Marker. 
A

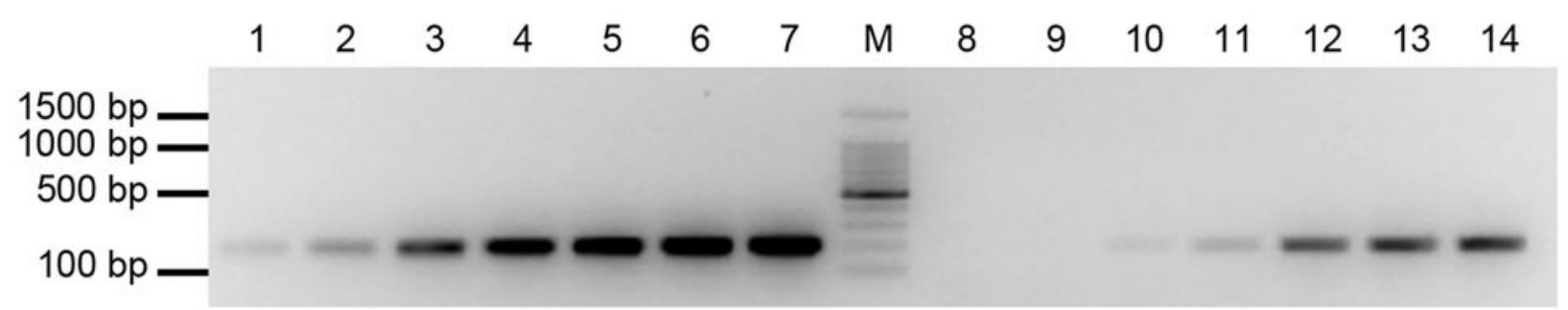

B

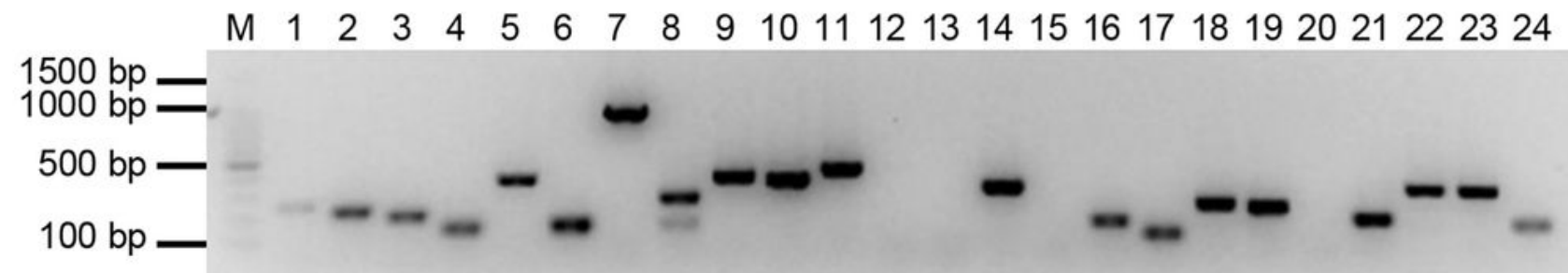

C

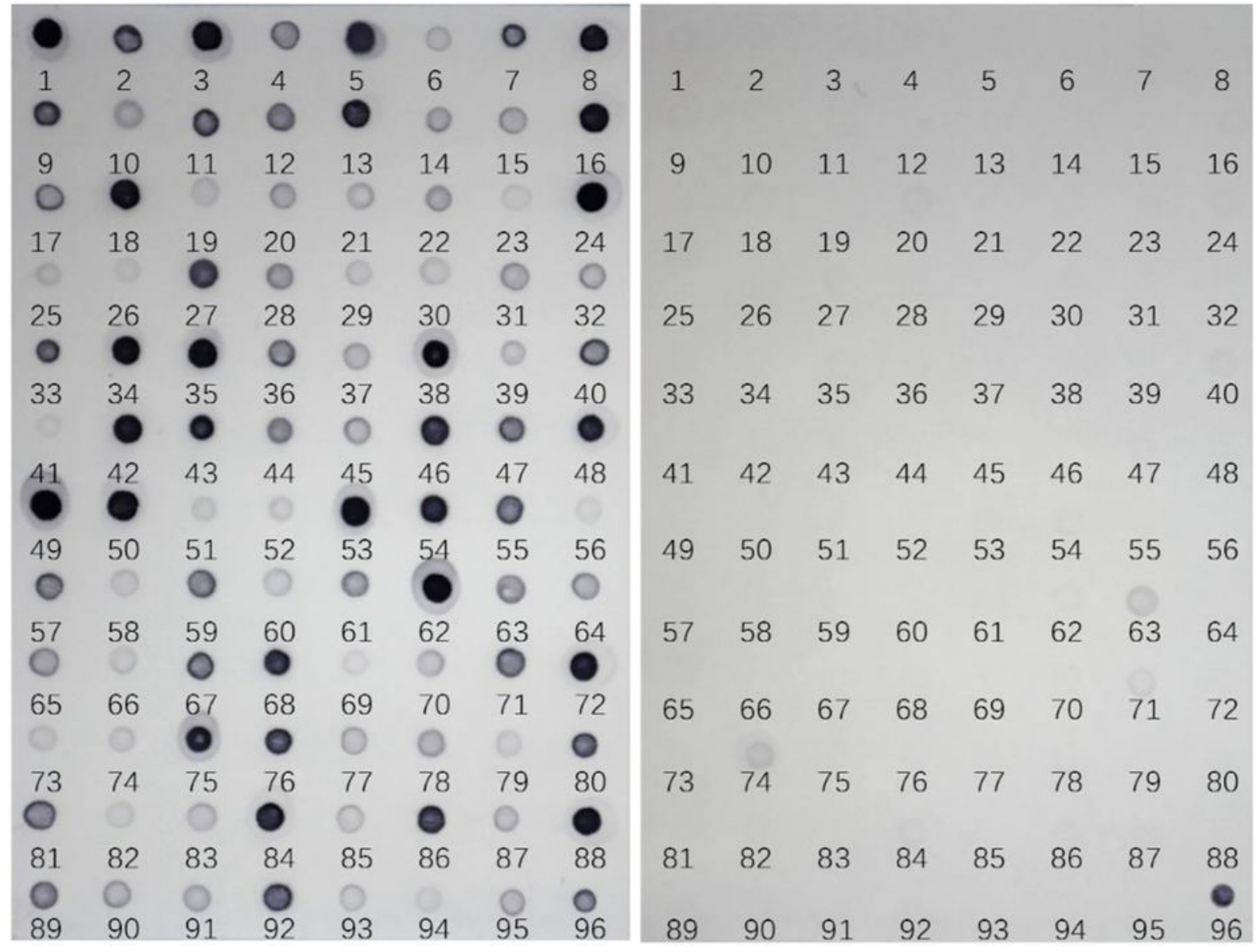

Figure 2

The detection of PCR and dot-blot screening of E. arundinaceus-specific clones. (A) The efficiency of suppression subtractive hybridization. M: 100bp Marker; 1-7: PCR was performed on unsubtracted secondary PCR products with amplification cycles of 18, 21, 24, 27, 30, 33, and 36; 8-14: PCR was performed on subtracted secondary PCR products with amplification cycles of 18,21,24, 27, 30, 33, and 36. (B) The detection result of positive clones. M: 100 bp DNA Ladder; 1-24: Randomly selected clones. 
(C) The detection result of RDB. The probe of gDNA from HN92-77 and sugarcane in left and right nylon membrane, respectively. The plasmid of 45S rDNA as positive control in No. 96.

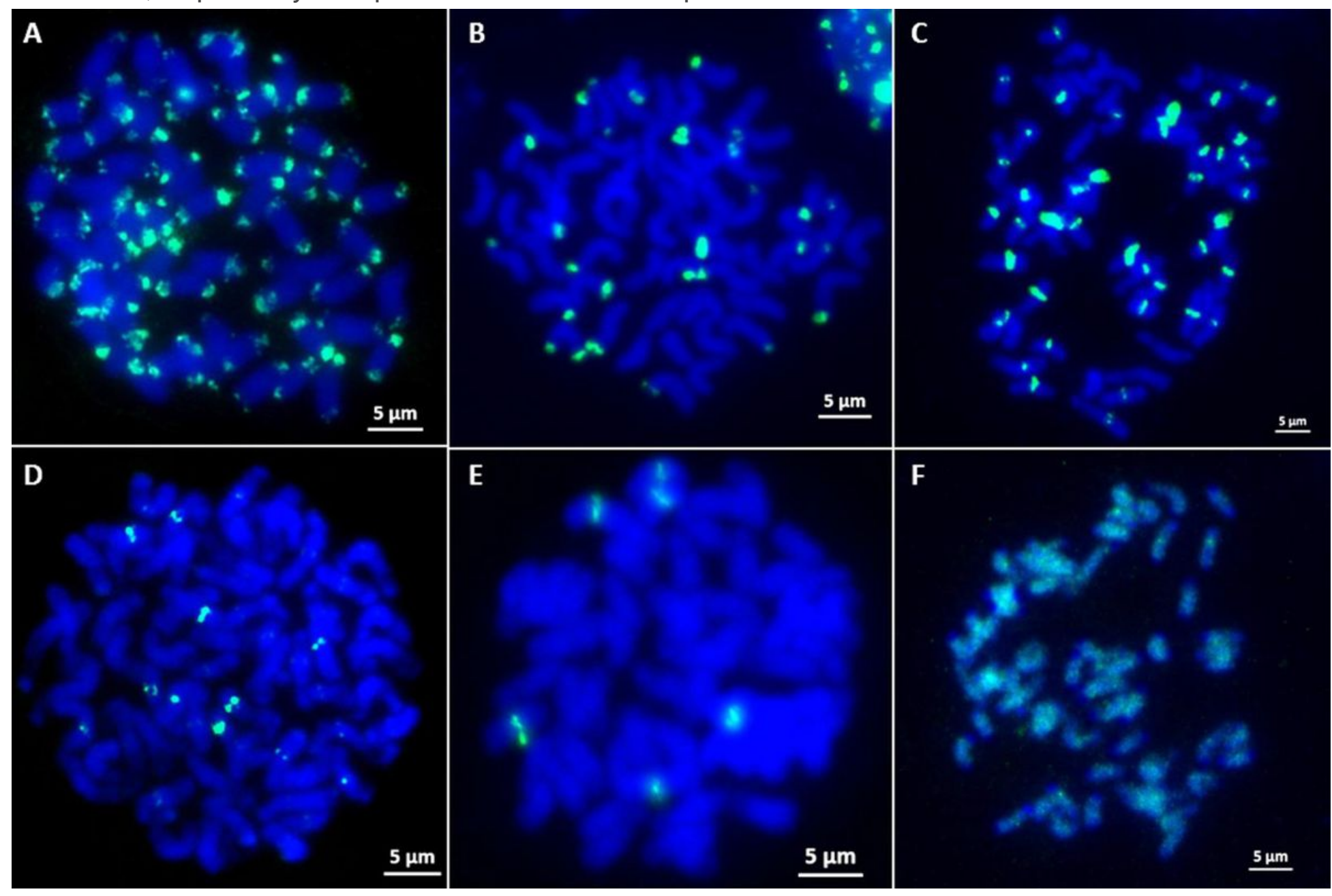

\section{Figure 3}

The FISH result of clones from SSH library. (A) The ends of most E. arundinaceus chromosomes; (B) The ends of a part of $\mathrm{E}$. arundinaceus chromosomes; (C) The centromeric region of most $\mathrm{E}$. arundinaceus chromosomes; (D) The centromeric region of a part of $E$. arundinaceus chromosomes; (E) The centromeric region of six E. arundinaceus chromosomes; (F) Diffuse distribute on all E. arundinaceus chromosomes, except for the ends of E. arundinaceus chromosomes. Scale bars $=5 \mu \mathrm{m}$. 


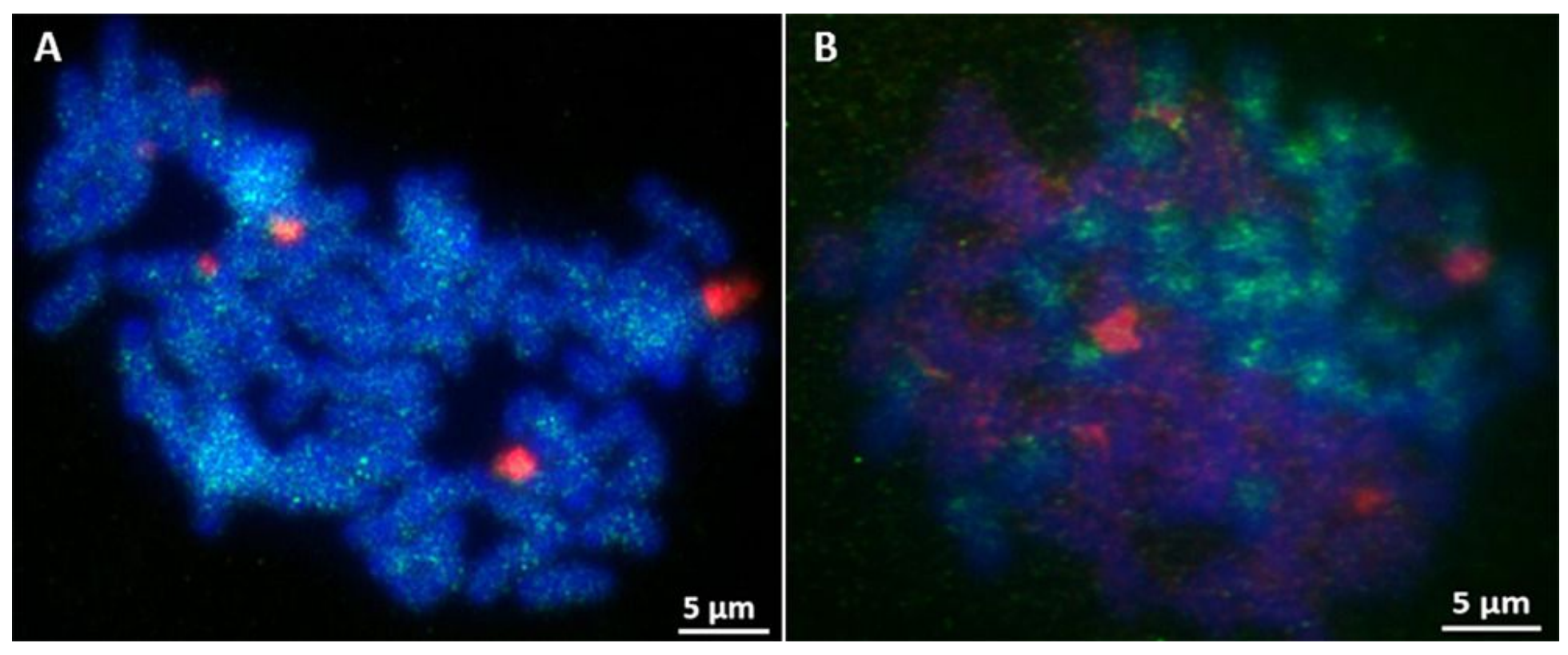

\section{Figure 4}

FISH result of clone Ea086 and 45S rDNA. (A) HN92-77; (B) YCE96-40. The probe of clone Ea086 was labelled with Dig (Green), the probes of both 45S rDNA and Badila gDNA were labelled with Biotin (Red), chromosomes were counterstained with DAPI (Blue). Scale bars $=5 \mu \mathrm{m}$.
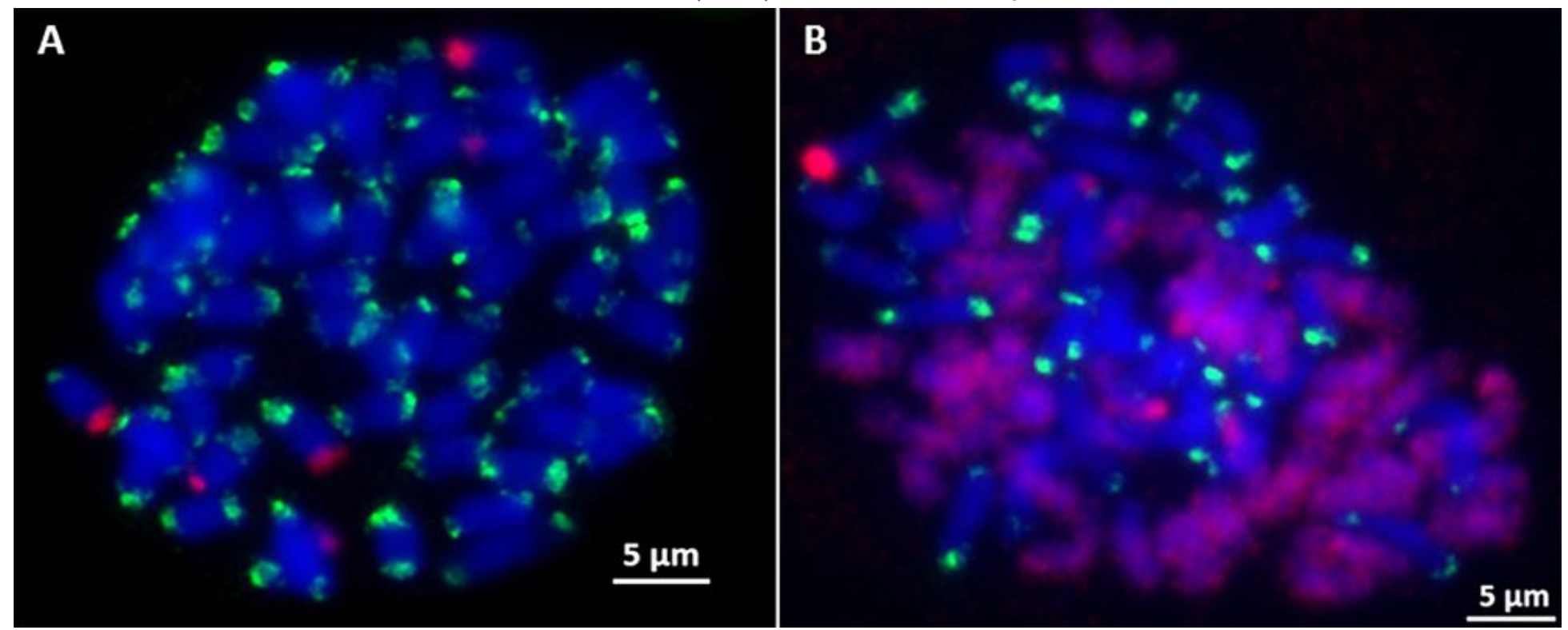

\section{Figure 5}

FISH result of clone Ea009 and 45S rDNA. (A) HN92-77; (B) YCE96-40. The probe of clone Ea009 was labelled with Dig (Green), the probes of both 45S rDNA and Badila gDNA were labelled with Biotin (Red), chromosomes were counterstained with DAPI (Blue). Scale bars $=5 \mu \mathrm{m}$. 


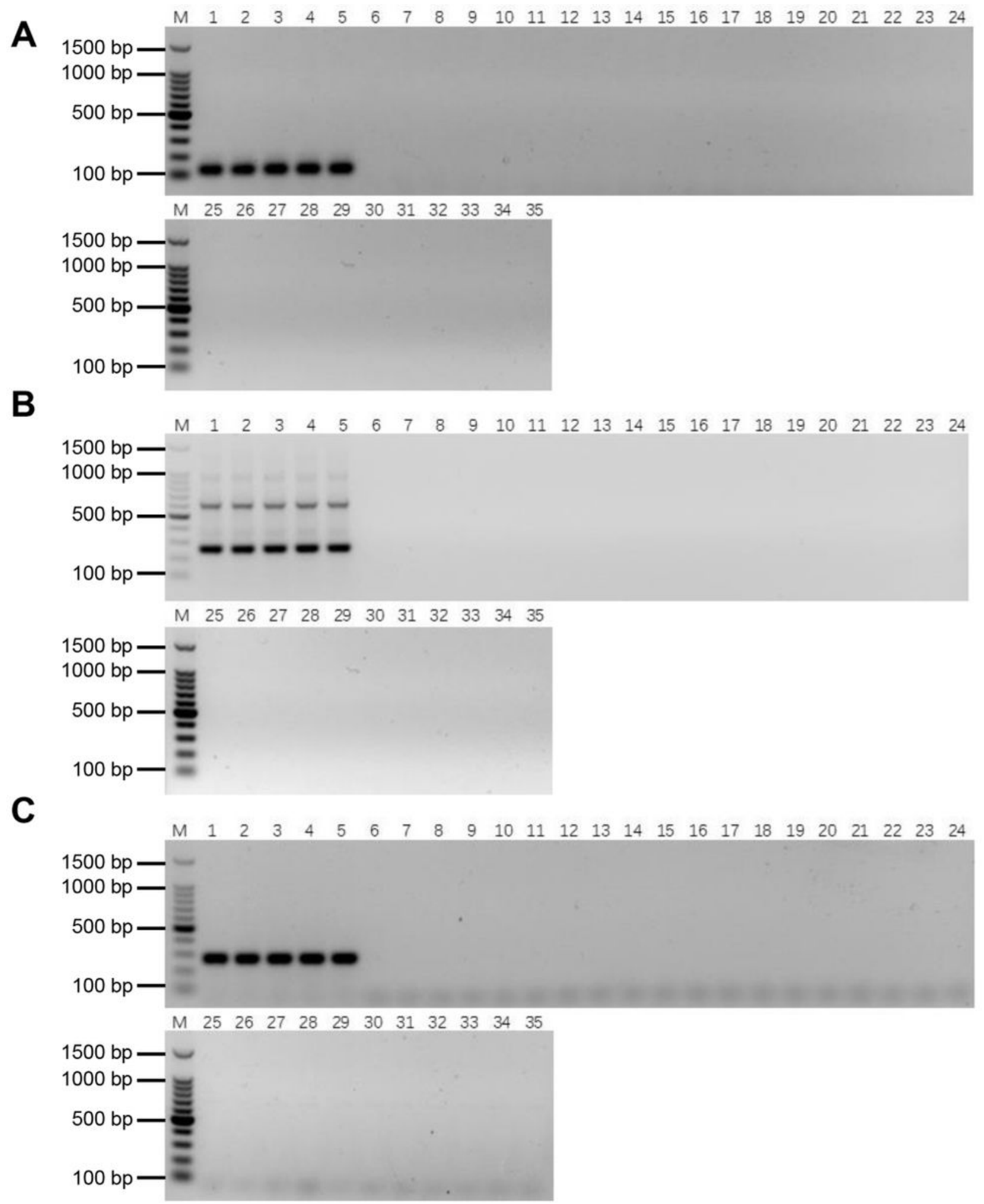

\section{Figure 6}

Validation of the specificity of E. arundinaceus-specific markers. (A) Ea086-128 primer; (B) Ea009-257 primer; (C) EalTS-278 primer. M: 100 bp DNA Ladder; 1-5: original species of E. arundinaceus; 6-10: S. officinarum; 11-15: S. robustum; 16-20: S. spontaneum; 21-25: S. sinense; 26-30: S. barberi; 31-35: Cultivars. All samples were listed in Table S1. 

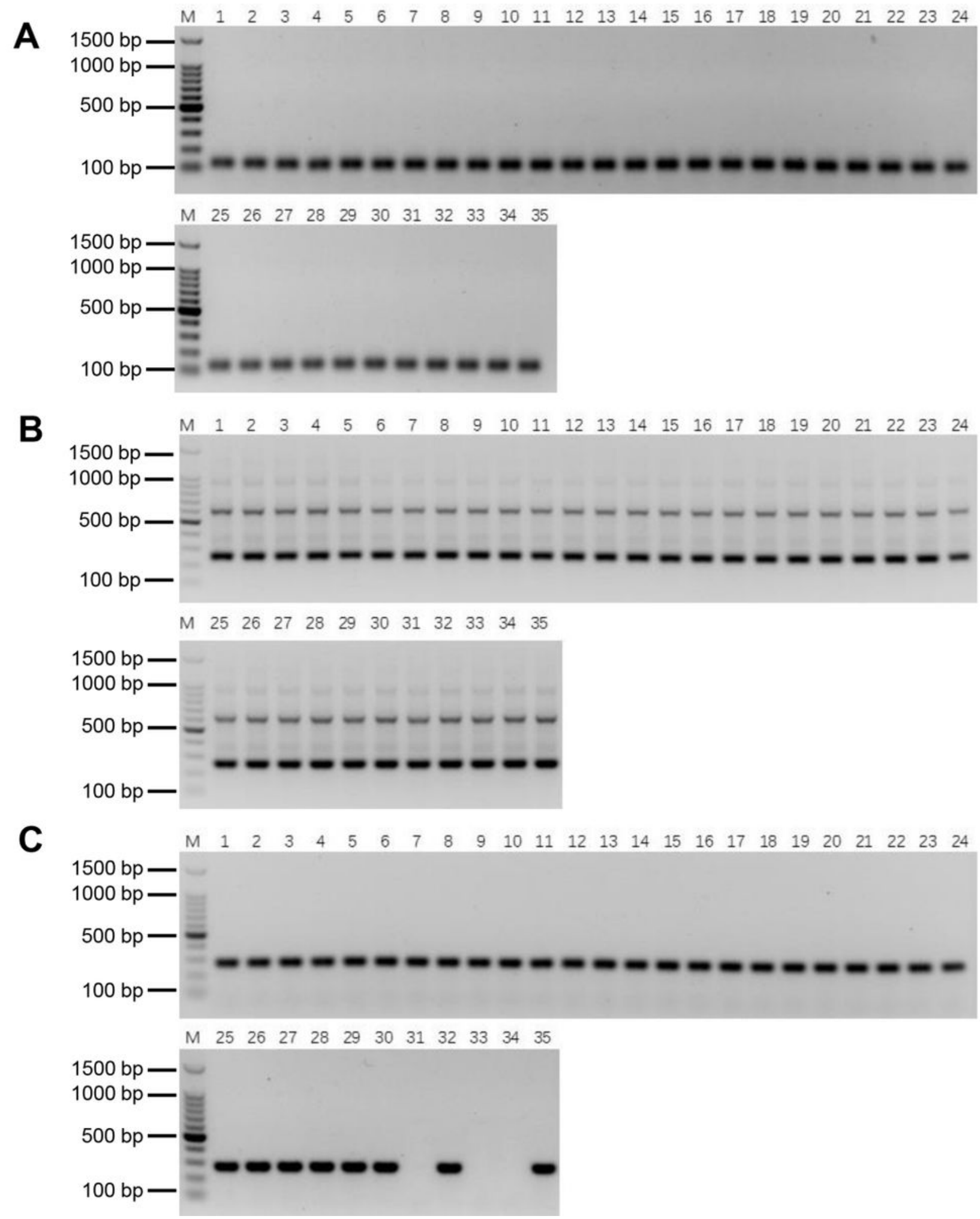

\section{Figure 7}

Validation of the stability of E. arundinaceus-specific markers. (A) Ea086-128 primer; (B) Ea009-257 primer; (C) EalTS-278 primer. M: 100 bp DNA Ladder; 1-5: F1 progeny between sugarcane and E. arundinaceus; 6-18: $\mathrm{BC} 1$ progeny between sugarcane and $\mathrm{E}$. arundinaceus; 19-27: $\mathrm{BC} 2$ progeny between sugarcane and E. arundinaceus; 28-35: BC3 progeny between sugarcane and E. arundinaceus. All samples were listed in Table S2. 


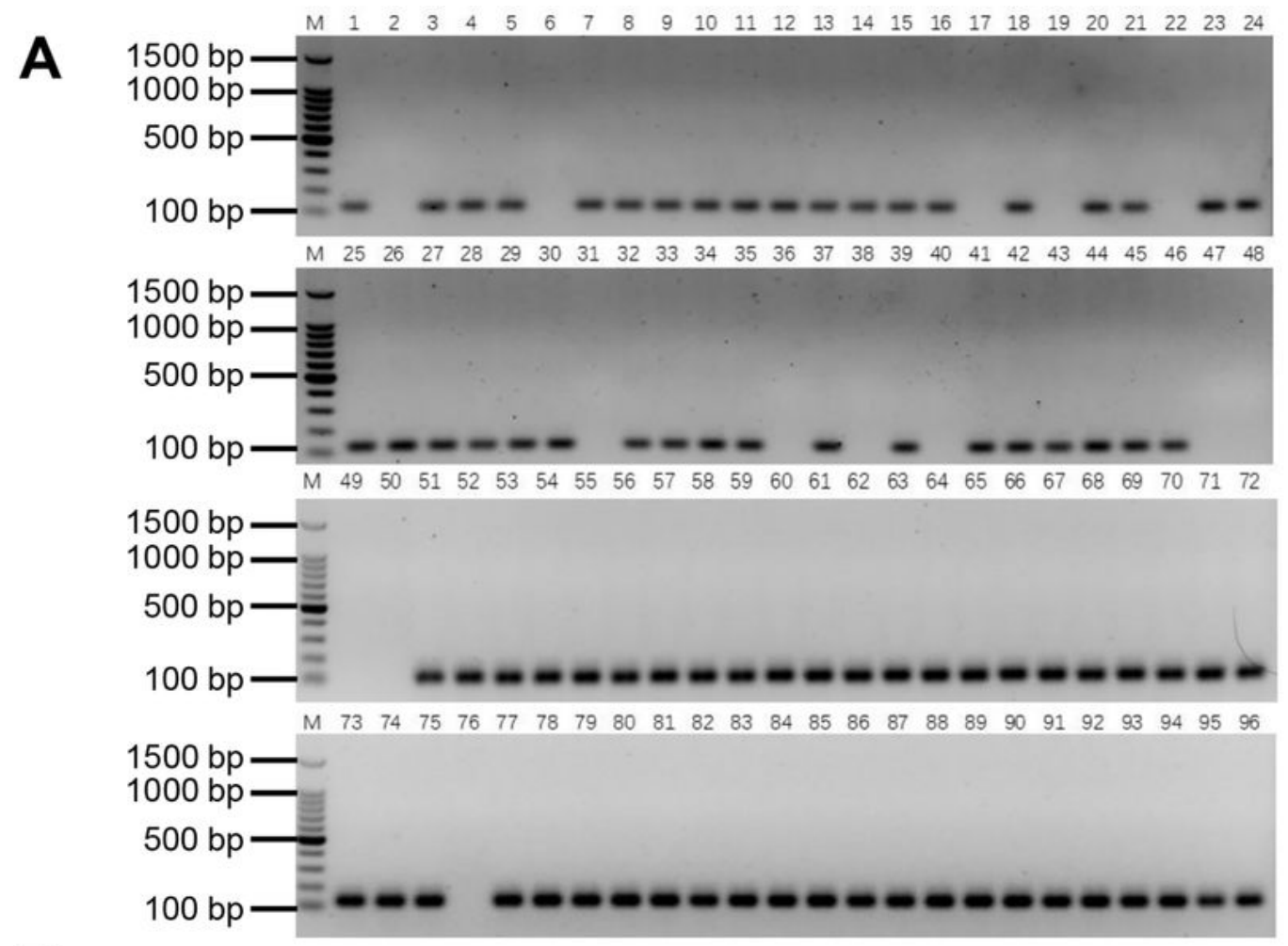

B

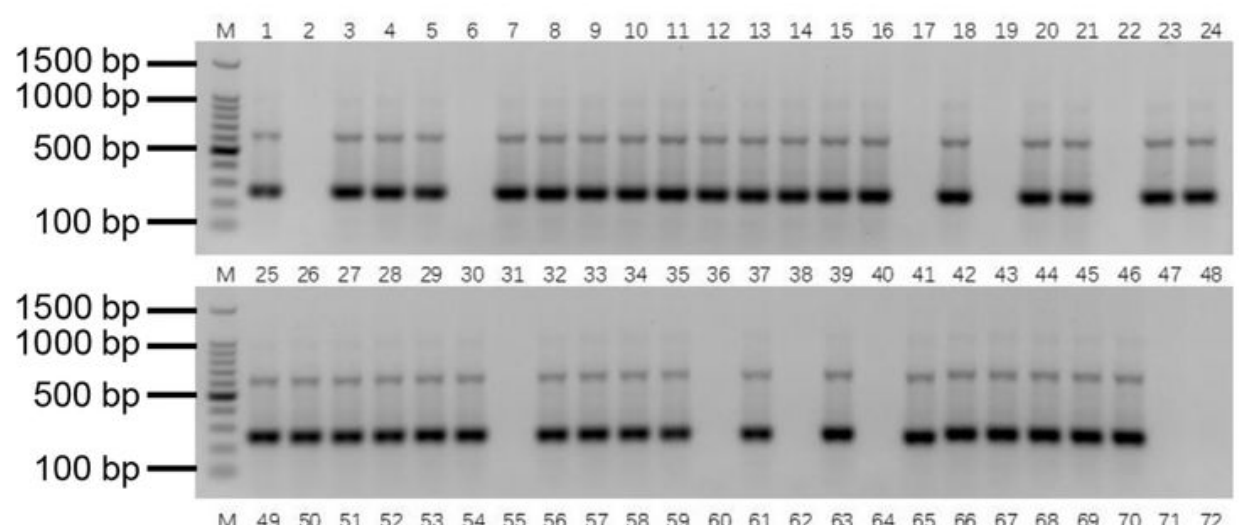

$\begin{array}{lllllllllllllllllllllllll}M & 49 & 50 & 51 & 52 & 53 & 54 & 55 & 56 & 57 & 58 & 59 & 60 & 61 & 62 & 63 & 64 & 65 & 66 & 67 & 68 & 69 & 70 & 71 & 72\end{array}$

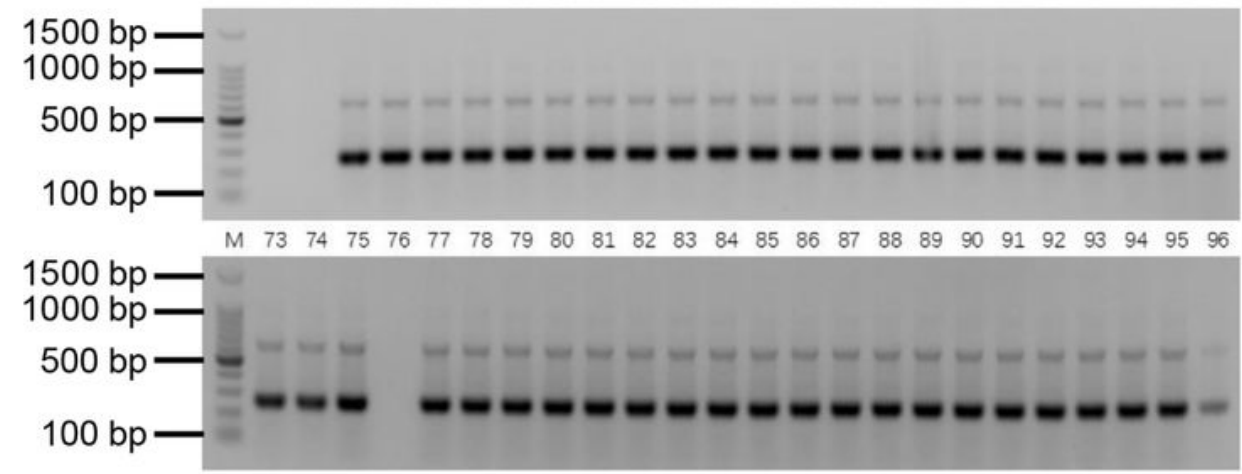

\section{Figure 8}

PCR detection result of putative BC4 progeny between sugarcane and E. arundinaceus. (A) Ea086-128 primer; (B) Ea009-257 primer. M: 100 bp DNA Ladder; 1-24: Putative progeny between CP89-2143 and YCE06-61; 25-48: Putative progeny between CP94-1100 and YCE06-61; 49-72: Putative progeny between HoCP01-564 and YCE06-61; 73-96: Putative progeny between GT00-122 and YCE06-61. 


\section{Supplementary Files}

This is a list of supplementary files associated with this preprint. Click to download.

- SupplementaryFiles.docx

- Additionalfiles.pptx 